\title{
Pectoralis Muscle
}

National Cancer Institute

\section{Source}

National Cancer Institute. Pectoralis Muscle. NCI Thesaurus. Code C33286.

Muscles of the upper chest. The term may refer to one of two muscles, the pectoralis major and pectoralis minor. The former is a thick muscle in the anterior portion of the chest. Its action involves flexion, medial rotation, and adduction of the humerus. The latter is a thin muscle located beneath the pectoralis major. Its action involves lowering the scapula and raising the ribs. 